\title{
Neuropeptide Y in the Adult and Fetal Human Pineal Gland
}

\author{
Morten Møller, ${ }^{1}$ Pansiri Phansuwan-Pujito, ${ }^{2}$ and Corin Badiu ${ }^{3}$ \\ ${ }^{1}$ Department of Neuroscience and Pharmacology, Laboratory of Neuropsychiatry, University of Copenhagen, \\ 2100 Copenhagen, Denmark \\ ${ }^{2}$ Department of Anatomy, Faculty of Medicine, Srinakharinwirot University, Bangkok 10110, Thailand \\ ${ }^{3}$ National Institute of Endocrinology, "C. Davila” University of Medicine and Pharmacy, 050474 Bucharest, Romania \\ Correspondence should be addressed to Morten Møller; morm@sund.ku.dk
}

Received 16 December 2013; Accepted 10 February 2014; Published 17 March 2014

Academic Editor: Yoav Gothilf

Copyright ( $\odot 2014$ Morten Møller et al. This is an open access article distributed under the Creative Commons Attribution License, which permits unrestricted use, distribution, and reproduction in any medium, provided the original work is properly cited.

Neuropeptide Y was isolated from the porcine brain in 1982 and shown to be colocalized with noradrenaline in sympathetic nerve terminals. The peptide has been demonstrated to be present in sympathetic nerve fibers innervating the pineal gland in many mammalian species. In this investigation, we show by use of immunohistochemistry that neuropeptide $\mathrm{Y}$ is present in nerve fibers of the adult human pineal gland. The fibers are classical neuropeptidergic fibers endowed with large boutons en passage and primarily located in a perifollicular position with some fibers entering the pineal parenchyma inside the follicle. The distance from the immunoreactive terminals to the pinealocytes indicates a modulatory function of neuropeptide Y for pineal physiology. Some of the immunoreactive fibers might originate from neurons located in the brain and be a part of the central innervation of the pineal gland. In a series of human fetuses, neuropeptide Y-containing nerve fibers was present and could be detected as early as in the pineal of four- to five-month-old fetuses. This early innervation of the human pineal is different from most rodents, where the innervation starts postnatally.

\section{Introduction}

The pineal gland of mammals is an endocrine gland secreting the hormone melatonin with a circadian rhythm exhibiting a zenith during the night time $[1,2]$. The synthesis of melatonin is regulated by a dense network of sympathetic nerve fibers originating from perikarya located in the autonomic superior cervical ganglia $[3,4]$. Most of these sympathetic nerve fibers do also costore neuropeptide Y (NPY).

NPY was originally isolated from the porcine hypothalamus [5] and later found to be colocalized with noradrenaline in most sympathetic fibers [6] including the nerve fibers innervating the rat pineal gland [6-10].

The sequence of the NPY gene encodes a pre-pro NPY, a precursor peptide of 97 amino acids, which is cleaved into the pro-NPY, a 69 -aa peptide [11]. The pro-NPY molecule is posttranslationally processed by a single cleavage to neuropeptide Y (NPY) and a C-terminal peptide of NPY (CPON). NPY is Cterminally amidated, and the amidation is essential for binding of NPY to its corresponding receptors [12].
A few of the NPYergic nerve fibers innervating especially the rostral part of the rat pineal gland do not originate from perikarya in the superior cervical ganglia $[8,9,12,13]$. Thus, some NPY-containing nerve fibers remain in the gland after bilateral superior cervical ganglionectomy [12] and these fibers might originate from neurons located in the brain itself (pineal central innervations). Ultrastructural analysis using immunocytochemistry has shown NPY to be confined in the large dense core granules in the sympathetic nerve terminals [12].

The NPYergic innervation of the mammalian pineal has later been confirmed in numerous mammalian species, for example, cotton rat [14], Golden hamster [15], European hamster [16], guinea pig [17], gerbil [13], mink [18], chinchilla [19], tree shrew [20], brown bat [21], sheep [22, 23], cat [24], pig $[25,26]$, cow $[27,28]$, and monkey [29].

Release of noradrenaline in the pineal gland starts a biochemical cascade, which includes binding of the transmitter to beta-adrenergic receptors and initiation of the cAMP second messenger system, which has been thoroughly 
described [30]. However, what happens after release of NPY in the pineal gland is still a matter of discussion.

Melatonin is also synthesized in and secreted from the human pineal gland [31] and removal of the sympathetic input to the gland inhibits the elevated night time excretion of the hormone [32]. There has been a single report on the presence of a few NPY-immunoreactive fibers in the human pineal gland [33]. We have in this investigation performed a detailed study of the presence of the NPYergic innervations in adult human pineal obtained at autopsy and included a series of human fetal pineal gland obtained by caesarian sections. We show the presence of dense NPYergic innervations in adult pineal gland. An NPYergic innervation is also present in human fetal pineals where the first immunoreactive nerve fibers were observed in the 4 th fetal month.

\section{Materials and Methods}

2.1. Antisera and Peptides. The primary Rabbit antisera against NPY used in the present investigation (numbers 8182 and 337) have been characterized previously $[34,35]$. Antisera against the C-terminal flanking peptide of NPY $(\mathrm{CPON})$ were purchased from Cambridge Research Biochemical (Cheshire, $\mathrm{UK})$.

Biotinylated swine antirabbit IgG was obtained from Dako, Glostrup, Copenhagen (number E353). The ABCstreptavidin-horseradish peroxidase complex was obtained from Vector, Burlingame, CA, USA. (Vectastain Elite ABC kit, number PK-6100)

2.2. Adult Human Pineal Gland. A series of human pineal glands of both sexes were obtained from hospital autopsies. The age varied from 6 to 82 years. The postmortem time before fixation varied from 12 to 36 hours.

The brains were removed and the epithalamic area was dissected from the brain and immersed in cold $\left(4^{\circ} \mathrm{C}\right) 4 \%$ paraformaldehyde in $0.1 \mathrm{M}$ phosphate buffer ( $\mathrm{pH}$ 7.4) for 5 days. The tissue blocks were then infiltrated with a solution of $30 \%$ sucrose in phosphate buffered saline (PBS) for 3 days and $18 \mu \mathrm{m}$ or $40 \mu \mathrm{m}$ thick serial cryostat sections were cut into sagittal and coronal planes. The $40 \mu \mathrm{m}$ thick sections were transferred to $\mathrm{PBS}$ at $4^{\circ} \mathrm{C}$. The $18 \mu \mathrm{m}$ thick sections were placed on gelatinized glass slides.

2.3. Human Fetal Brains. The material examined was obtained from legal abortions and consisted of pineal glands from human fetuses of both sexes. The gestational ages were from 2.5 months ( 9 weeks) to 6 months ( 24 weeks). The postmortem interval preceding fixations varied, but in most cases the brains were immersed in cold $\left(4^{\circ} \mathrm{C}\right) 4 \%$ paraformaldehyde in $0.1 \mathrm{M}$ phosphate buffer ( $\mathrm{pH}$ 7.4) for less than 30 minutes after removal from the uterus. Two extensive sagittal cuts were made in each hemisphere to ensure good penetration of the fixative into the brain ventricular system. The brains were cryoprotected in $30 \%$ sucrose as described above, frozen in crushed $\mathrm{CO}_{2}$, and cut into sagittal or coronal, $18 \mu \mathrm{m}$ thick, cryostat sections.
2.4. Immunohistochemistry. The sections were processed for immunohistochemistry by the use of the streptavidin enzyme histochemical technique. The $40 \mu \mathrm{m}$ thick sections were reacted as free floating sections and the $18 \mu \mathrm{m}$ thick sections were reacted on the glass slides in a humid chamber. The sections were rinsed twice for $5 \mathrm{~min}$ in PBS and pretreated in $1 \% \mathrm{H}_{2} \mathrm{O}_{2}$ in PBS for $10 \mathrm{~min}$. They were then incubated for $20 \mathrm{~min}$ in a $4 \%$ swine serum solution in PBS containing $0.3 \%$ Triton $\mathrm{X}-100$ and $1 \%$ bovine serum albumin. This was followed by incubation in the primary antiserum for $24 \mathrm{~h}$ at $4^{\circ} \mathrm{C}$. The dilutions were as follows: NPY (antisera numbers 337 and 8182), 1:1,000; CPON, 1:2,000. The sections were then washed in PBS to which $0.25 \%$ bovine serum albumin and $0.1 \%$ Triton X-100 were added (PBS-BT) for $3 \times 10 \mathrm{~min}$ followed by incubation with the biotinylated swine antirabbit IgG, diluted 1:400 in PBS-BT, for $60 \mathrm{~min}$ at room temperature. They were next washed for $3 \times 10 \mathrm{~min}$ in KPBSBT and finally incubated for $60 \mathrm{~min}$ at room temperature in an ABC-streptavidin-horseradish peroxidase complex 1:500 in PBS-BT. After washing in KPBS-BT for $10 \mathrm{~min}$, in KPBS alone for $10 \mathrm{~min}$, and in $50 \mathrm{mM}$ Tris/ $\mathrm{HCl}$ buffer $(\mathrm{pH}$ 7.6) for $10 \mathrm{~min}$, the sections were reacted for peroxidase activity by incubation with a solution of $1.25 \mathrm{mg} / \mathrm{L}$ diaminobenzidine (DAB) in $0.05 \mathrm{M}$ Tris/HCl-buffer (pH 7.6) and $0.003 \% \mathrm{H}_{2} \mathrm{O}_{2}$ for $20 \mathrm{~min}$. After washing for $2 \times 5 \mathrm{~min}$ in distilled water, the sections were mounted on gelatinized glass slides, dried, dehydrated in a series of ethanols, and embedded in Depex. Some adjacent sections were counterstained in thionine after the $\mathrm{DAB}$ reaction.

Absorption controls were done by substituting the primary antisera with antisera preabsorbed for $48 \mathrm{hr}$ with the specific antigen $(100 \mu \mathrm{g} / \mathrm{mL}$ diluted antiserum $)$ at $4^{\circ} \mathrm{C}$.

\section{Results}

3.1. Adult Human Pineal Glands. The adult human pineal is located on the dorsal part of the brain stem at the mesodiencephalic border connected to the epithalamic area with a short broad stalk (Figure 1(a)). The gland varies in size and often develops calcifications in adult; it is about $12 \mathrm{~mm}$ height, $7 \mathrm{~mm}$ in width, and about $6 \mathrm{~mm}$ in anteriorposterior direction. The third ventricle makes an evagination; the pineal recess into the stalk and separates the rostral habenular area from the posterior commissure caudal to the gland.

The pineal parenchyma, consisting of pinealocytes, interstitial cells, phagocytes, and capillaries, is arranged into large folliculi separated by septae of connective tissue and blood vessels.

Numerous NPY-immunoreactive nerve fibers endowed with large boutons en passage were present in a perifollicular position (Figures 2(a) and 2(b)). Some of the immunoreactive nerve fibers penetrated into the follicle itself, but a dense innervation of the follicle itself was not present.

Several immunoreactive nerve fibers were present in the pineal stalk and some of these immunoreactive nerve fibers entered the rostral part of the pineal gland. 


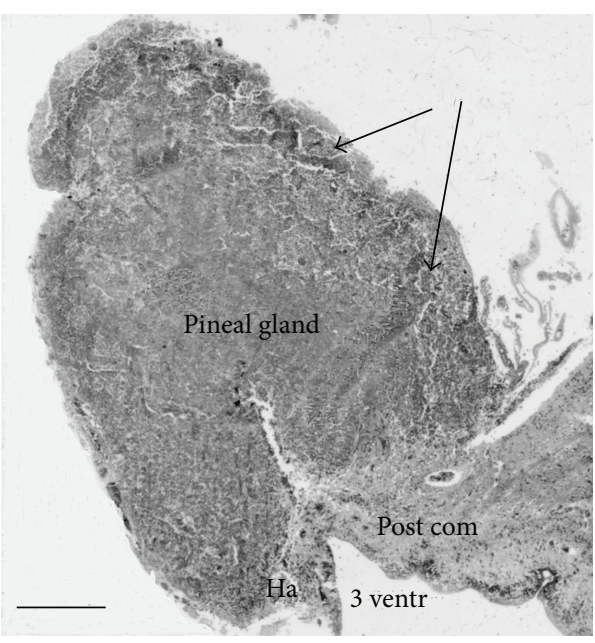

(a)

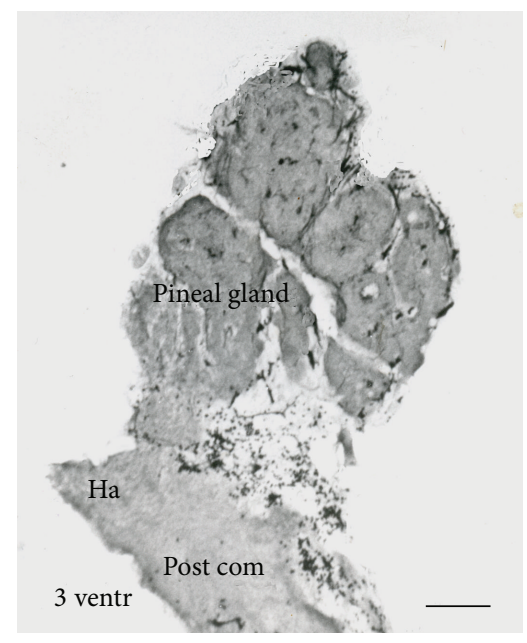

(b)

Figure 1: (a) Sagittal section of a human pineal gland of a young adult obtained at autopsy. The pineal recess is seen below the gland and some pial tissue is located caudal to the gland. Note the follicular appearance of the pineal parenchyma (arrows). Bar $=1 \mathrm{~mm}$. (b) Sagittal section of a 7-month-old human fetus. Note the follicular appearance of the parenchyma. Bar $=250 \mu \mathrm{m}$. Ha: habenula, Post com: posterior commissure, and 3 ventr: third ventricle.

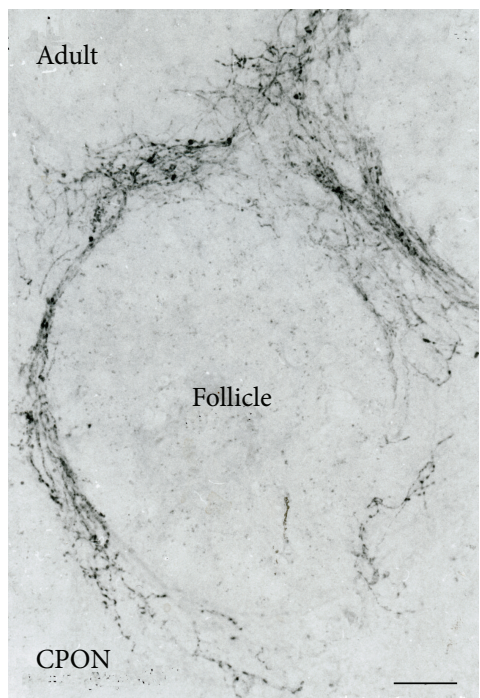

(a)

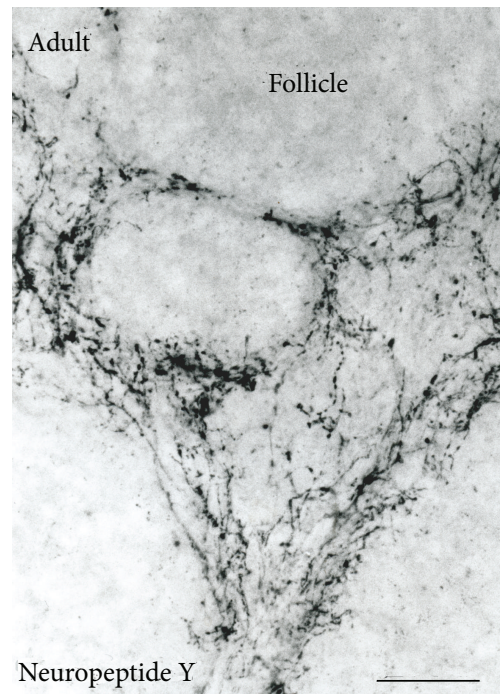

(b)

FIgURE 2: (a) and (b) Photomicrographs of parts of the adult human pineal gland obtained at autopsy, which have been immunoreacted for CPON (a) and NPY (b). Note in both pineals the perifollicular location of NPY-immunoreactive nerve fibres with large boutons en passage. Several of the nerve fibres penetrate into the follicle. Bars $=250 \mu \mathrm{m}((\mathrm{a})$ and (b)).

3.2. Fetal Pineal Glands. The human fetal pineal gland develops in the second month of gestation as an evagination of the ependyma covering the third ventricle at the diencephalicmesencephalic border [36, 37]. The cell proliferation of the ependymal cells gives rise toto an anterior- and posterior "anlage" (lobe) which later are merging. In the third gestational month, the pineal is macroscopically visible (Figure 3 ). The follicular appearance of the pineal parenchyma is clearly visible (Figure 1(b)).
The NPYergic innervation of the fetal pineal with gestational ages of 6 to 7 months was quite dense (Figure 4(a)). The number of NPYergic immunoreactive nerve fibers declined in the 5-month-old fetuses (Figure 4(b)), and in the 4th gestational month only few and thin immunoreactive fibers were observed. In our series, we did not stain immunoreactive nerve fibers in fetuses younger than 4th gestational month.

There was a clear relationship between the postmortem time of the tissue before fixation and the immunoreactivity 


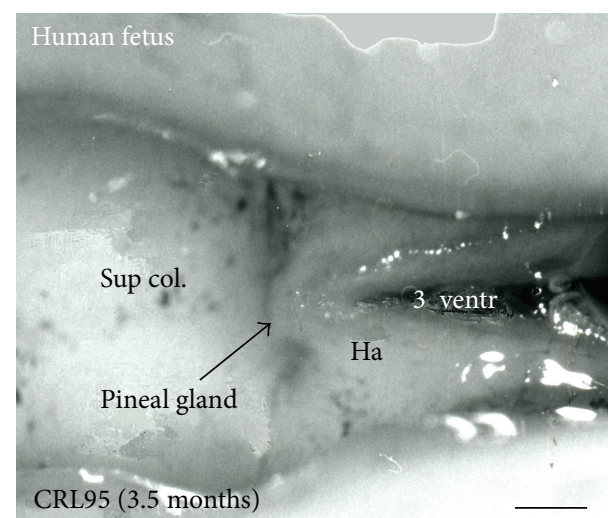

FIGURE 3: Superior (dorsal) view of the diencephalic-mesencephalic area of a 3.5-month-old human fetus. The third ventricle (3 ventr) without pial covering is seen to the right in the micrograph. The small pineal gland is a small protuberance (arrow) and merging via the broad stalk with the habenula ( $\mathrm{Ha})$. Sup col.: superior colliculus. Bar $=2 \mathrm{~mm}$.

of the nerve fibers in the tissue sections. The morphological best fibers were obtained in the pineals which were fixed with the shortest time delay.

\section{Discussion}

We show in this paper dense NPYergic innervations of both the adult and fetal human pineal glands with classical neuropeptidergic nerve fibers endowed with large boutons en passage. The prominent perifollicular distribution of the nerve fibers in the human is different from the distribution seen in several other rodent and nonrodent species, where many of the NPYergic nerve fibers penetrate into the pineal parenchyma between the pinealocytes. Due to the delay caused by the diffusion distance from the perifollicular terminals to the pinealocytes, this might indicate a modulatory function for NPY in human pineal biochemistry. The majority of the NPYergic nerve fibers are probably originating from sympathetic nerve fibers in the superior cervical ganglion. However, the evidence of a sympathetic innervation of the human pineal gland is indirect because a superior cervical ganglionectomy in humans has never been performed. However, in tetraplegic patients, with total transverse lesions of the cervical spinal cord, the night time elevation of plasma melatonin is abolished [38-41]. This indicates that intact nerve fibers in the cervical parts of the spinal cord are a prerequisite for the presence of a circadian rhythm of melatonin secretion. Further, transection of the sympathetic trunk at the level of the second thoracic ganglion in patients to prevent hyperhidrosis abolishes the night time elevation of melatonin secretion in the majority of these patients [32].

The current study also showed many NPYergic nerve fibers in pineal stalk of both the adult and fetal pineals and might indicate the presence of NPYergic nerve fibers innervating of the human pineal from the brain via the pineal stalk. Such a central pineal innervation in mammals has been a matter of controversy. Early studies in humans described the presence of silver stained nerve fibers penetrating into the pineal gland via the stalk from the habenular and posterior commissures [42]. However, in later studies of the rat it was suggested that these fibers looped in the rostral part of the pineal and returned to the brain without making functional contacts [43]. Contrarily, lesions of the habenular area in the rat resulted in anterograde degenerating nerve fibers in the pineal gland [44]. Later, retro- and anterograde in vivo tracings of fibers innervating the pineal gland showed the origin of these central fibers to be located in the paraventricular nucleus [45] as well as in neurons located in the lateral geniculate body of the thalamus $[46,47]$. In rodents, the intergeniculate leaflet of the lateral geniculate body contains NPYergic neurons, which projects to the SCN and is responsible for a nonphotic regulation of the endogenous clock [48]. It is possible that some NPYergic neurons in the intergeniculate leaflet also project to the pineal gland.

A parasympathetic innervation of the pineal gland is also present $[49,50]$. NPY also been found to be colocalized with acetylcholine in parasympathetic ganglia known to project to the pineal gland [51]. Therefore, the parasympathetic system might contribute to the pineal NPYergic innervation.

The physiological function of NPY in the pineal gland is not clear. There is no direct stimulatory effect of NPY on the secretion of melatonin in cultures, but NPY has an indirect effect by inhibiting the stimulatory effect of noradrenaline on melatonin release $[52,53]$. The effect of NPY on the noradrenergic transmission is probably transmitted via inhibitory G-proteins in the membrane reducing the activity of adenylate cyclase in the target cells $[54,55]$. The cells possessing receptors for NPY in the pineal gland have not been determined, but specific binding sites have been demonstrated in suspensions of cultured pineal cells [52], indicating that postsynaptic receptors are present in the pineal gland. Further evidence has shown that the NPY binding site is of the Y1 subtype [53], which is supported by reverse-transcriptase polymerase chain reaction studies, showing that only Y1 mRNA, and not any of the other subtypes (Y2, Y4, or Y5) was expressed [56].

The detection of weakly stained NPYergic fibers in fourmonth-old fetal pineal is in accord with studies on NPY in other regions of the brain, demonstrating that NPY can be detected around the 4 th fetal month and that the number of NPYergic neurons increases with fetal age [57]. In a study of human fetal spinal cords NPY-immunoreactive neurons were found in the dorsal horn as early as 10 weeks of fetal age [58].

From the physiological point of view there are indications in the European hamster (Cricetus cricetus) that NPY might control annual rhythms. Thus, the number of NPYergic intrapineal nerve fibers exhibits an annual rhythm with a zenith in midwinter [16]. At midwinter 5-methoxytryptophol starts to exhibit a nycthemeral rhythm and the activity of hydroxyindole-O-methyltransferase (HIOMT), a key enzyme in the synthesis of melatonin, is significantly increased [59]. In the rat, NPY stimulates HIOMT activity [60]. If NPY also stimulates HIOMT in the European hamster, NPY might be directly involved in the annual regulation of the pineal gland in this species. 


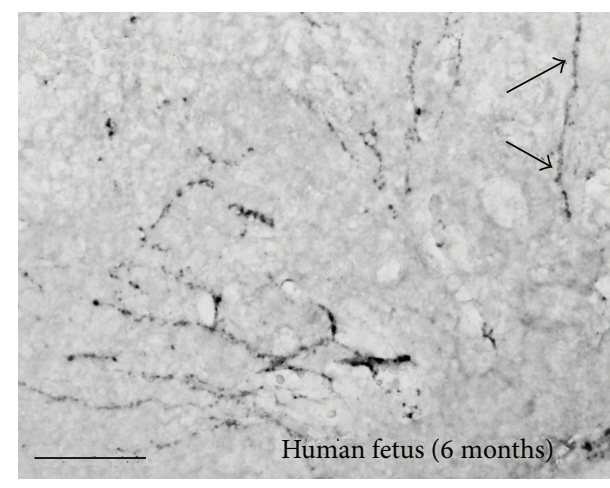

(a)

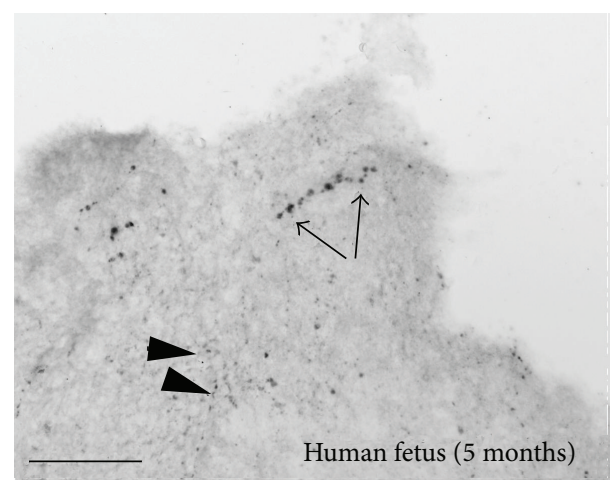

(b)

Figure 4: Photomicrographs of parts of human fetal pineal glands reacted immunohistochemically for neuropeptide Y. (a) Pineal gland from 6-month-old fetus. Arrows mark a long NPY-immunoreactive nerve fiber with large boutons en passage. (b) Pineal gland from 5-month-old fetus. Arrows mark an immunoreactive nerve fiber with large boutons en passage. Arrow heads point toward smaller immunoreactive boutons. Bar $=200 \mu \mathrm{m}$.

In summary, this paper shows the presence of dense innervations of the human pineal gland with classical neuropeptidergic NPY-immunoreactive nerve fibers. The NPYergic innervation of the human pineal gland starts in fetal life at about the 4th month of gestation.

\section{Conflict of Interests}

The authors declare that there is no conflict of interests regarding the publication of this paper.

\section{Acknowledgments}

This study was supported by the Lundbeck Foundation and the Novo Nordisk Foundation to Morten Møller and the Research fund of Srinakharinwirot University to P. Phansuwan-Pujito.

\section{References}

[1] R. J. Reiter, "Pineal melatonin: cell biology of its synthesis and of its physiological interactions," Endocrine Reviews, vol. 12, no. 2, pp. 151-180, 1991.

[2] J. H. Stehle, C. von Gall, and H.-W. Korf, "Melatonin: a clockoutput, a clock-input," Journal of Neuroendocrinology, vol. 15, no. 4, pp. 383-389, 2003.

[3] R. Y. Moore and D. C. Klein, "Visual pathways and the central neural control of a circadian rhythm in pineal serotonin $\mathrm{N}$ acetyltransferase activity," Brain Research, vol. 71, no. 1, pp. 1733, 1974.

[4] M. Møller and F. M. Baeres, "The anatomy and innervation of the mammalian pineal gland," Cell and Tissue Research, vol. 309, no. 1, pp. 139-150, 2002.

[5] K. Tatemoto, M. Carlquist, and V. Mutt, "Neuropeptide Y-a novel brain peptide with structural similarities to peptide YY and pancreatic polypeptide," Nature, vol. 296, no. 5858, pp. 659660, 1982.

[6] F. Schon, J. M. Allen, and J. C. Yeats, "Neuropeptide Y innervation of the rodent pineal gland and cerebral blood vessels,"
Neuroscience Letters, vol. 57, no. 1, pp. 65-71, 1985.

[7] J. M. Lundberg, L. Terenius, and T. Hokfelt, "Neuropeptide Y (NPY)-like immunoreactivity in peripheral noradrenergic neurons and effects of NPY on sympathetic function," Acta Physiologica Scandinavica, vol. 116, no. 4, pp. 477-480, 1982.

[8] S. Reuss and R. Y. Moore, "Neuropeptide Y-containing neurons in the rat superior cervical ganglion: projections to the pineal gland," Journal of Pineal Research, vol. 6, no. 4, pp. 307-316, 1989.

[9] R. E. Zigmond and Y. Sun, "Regulation of neuropeptide expression in sympathetic neurons. Paracrine and retrograde influences," Annals of the New York Academy of Sciences, vol. 814, pp. 181-197, 1997.

[10] E. Zhang, J. D. Mikkelsen, and M. Møller, "Tyrosine hydroxylase- and neuropeptide Y-immunoreactive nerve fibers in the pineal complex of untreated rats and rats following removal of the superior cercical ganglia," Cell and Tissue Research, vol. 265, no. 1, pp. 63-71, 1991.

[11] J. D. Mikkelsen and M. M. T. O’Hare, “An immunohistochemical and chromatographic analysis of the distribution and processing of proneuropeptide $\mathrm{Y}$ in the rat suprachiasmatic nucleus," Peptides, vol. 12, no. 1, pp. 177-185, 1991.

[12] J. D. Mikkelsen and M. Møller, "Neuropeptide Y in the mammalian pineal gland," Microscopy Research and Technique, vol. 46, no. 4-5, pp. 239-256, 1999.

[13] Y. Shiotani, M. Yamano, and S. Shiosaka, "Distribution and origins of substance P (SP)-, calcitonin gene-related peptide (CGRP)-, vasoactive intestinal polypeptide (VIP)- and neuropeptide $\mathrm{Y}$ (NPY)-containing nerve fibers in the pineal gland of gerbils," Neuroscience Letters, vol. 70, no. 2, pp. 187-192, 1986.

[14] S. Matsushima, Y. Sakai, Y. Hira, Y. Oomori, and S. Daikoku, "Immunohistochemical studies on sympathetic and nonsympathetic nerve fibers and neuronal cell bodies in the pineal gland of cotton rats, Sigmodon hispidus," Archives of Histology and Cytology, vol. 57, no. 1, pp. 47-58, 1994.

[15] H. Schröder, "Neuropeptide Y (NPY)-like immunoreactivity in peripheral and central nerve fibres of the golden hamster (Mesocricetus auratus) with special respect to pineal gland innervation," Histochemistry, vol. 85, no. 4, pp. 321-325, 1986.

[16] M. Møller, M. Masson-Pévet, and P. Pévet, "Annual variations of the NPYergic innervation of the pineal gland in the European 
hamster (Cricetus cricetus): a quantitative immunohistochemical study," Cell and Tissue Research, vol. 291, no. 3, pp. 423-431, 1998.

[17] H. Schroder and L. Vollrath, "Neuropeptide Y (NPY)-like immunoreactivity in the guinea pig pineal organ," Neuroscience Letters, vol. 63, no. 3, pp. 285-289, 1986.

[18] M. Møller, J. D. Mikkelsen, and L. Martinet, "Innervation of the mink pineal gland with neuropeptide Y (NPY)-containing nerve fibers. An experimental immunohistochemical study," Cell and Tissue Research, vol. 261, no. 3, pp. 477-483, 1990.

[19] M. Nowicki, J. Wojtkiewicz, B. Seremak et al., "Specific distribution pattern of nerve fibers containing catecholaminesynthesizing enzymes, neropeptide Y (NPY) and C-terminal flanking peptide of NPY (CPON) in the pineal gland of the chinchilla (Chinchilla laniger) —an immunohistochemical study," Folia Histochemica et Cytobiologica, vol. 41, no. 4, pp. 193-200, 2003.

[20] M. Kado, A. Yoshida, Y. Hira, Y. Sakai, and S. Matsushima, "Light and electron microscopic immunocytochemical study on the innervation of the pineal gland of the tree shrew (Tupaia glis), with special reference to peptidergic synaptic junctions with pinealocytes," Brain Research, vol. 842, no. 2, pp. 359-375, 1999.

[21] L. K. Laemle and J. R. Cotter, "Neuropeptide Y-like immunoreactivity in the diencephalon of the little brown bat (Myotis lucifugus): localized variations with physiological state," Journal of Comparative Neurology, vol. 316, no. 4, pp. 447-458, 1992.

[22] L. M. Williams, P. J. Morgan, G. Pelletier, G. I. Riddoch, W. Lawson, and G. R. Davidson, "Neuropeptide Y (NPY) innervation of the ovine pineal gland," Journal of Pineal Research, vol. 7, no. 4, pp. 345-353, 1989.

[23] B. Cozzi, J. D. Mikkelsen, J.-P. Ravault, and M. Møller, "Neuropeptide Y (NPY) and C-flanking peptide of NPY in the pineal gland of normal and ganglionectomized sheep," Journal of Comparative Neurology, vol. 316, no. 2, pp. 238-250, 1992.

[24] M. Møller, P. Phansuwan-Pujito, S. Pramaulkijja, N. Kotchabhakdi, and P. Govitrapong, "Innervation of the cat pineal gland by neuropeptide Y-immunoreactive nerve fibers: an experimental immunohistochemical study," Cell and Tissue Research, vol. 276, no. 3, pp. 545-550, 1994.

[25] B. Przybylska-Gornowicz, B. Lewczuk, and M. Møller, "Demonstration of nerve fibers containing the C-terminal flanking peptide of neuropeptide $\mathrm{Y}(\mathrm{CPON})$ in the pig pineal gland (Sus domesticus): an immunocytochemical study by light and electron microscopy," Anatomical Record, vol. 248, no. 4, pp. 576-782, 1997.

[26] M. Bulc, B. Lewczuk, M. Prusik, and J. Całka, “The foetal pig pineal gland is richly innervated by nerve fibres containing catecholamine-synthesizing enzymes, neuropeptide Y (NPY) and C-terminal flanking peptide of NPY, but it does not secrete melatonin," Histolology Histopathology, vol. 28, no. 5, pp. 633646, 2013.

[27] P. Phansuwan-Pujito, S. Pramaulkijja, P. Govitrapong, and M. Møller, "An immunohistochemical study of neuropeptide $\mathrm{Y}$ in the bovine pineal gland," Journal of Pineal Research, vol. 15, no. 1, pp. 53-58, 1993.

[28] S. Regodón and V. Roncero, "Embryonic development of the bovine pineal gland (Bos taurus) during prenatal life (30 to 135 days of gestation)," Histology and Histopathology, vol. 20, no. 4, pp. 1093-1103, 2005.

[29] J. D. Mikkelsen and G. Mick, "Neuropeptide Y-immunoreactive nerve fibres in the pineal gland of the macaque (Macaca fascicularis)," Journal of Neuroendocrinology, vol. 4, no. 6, pp. 681-688, 1992.

[30] E. Maronde, M. Pfeffer, C. Von Gall et al., "Signal transduction in the rodent pineal organ: from the membrane to the nucleus," Advances in Experimental Medicine and Biology, vol. 460, pp. 109-131, 1999.

[31] K. Ackermann and J. H. Stehle, "Melatonin synthesis in the human pineal gland: advantages, implications, and difficulties," Chronobiology International, vol. 23, no. 1-2, pp. 369-379, 2006.

[32] M. Møller, O. Osgaard, and M. Grønbech-Jensen, "Influence of sympathectomy in humans on the rhythmicity of 6sulphatoxymelatonin urinary excretion," Molecular and Cellular Endocrinology, vol. 252, no. 1-2, pp. 40-45, 2006.

[33] R. Y. Moore and P. Sibony, "Enkephalin-like immunoreactivity in neurons in the human pineal gland," Brain Research, vol. 457, no. 2, pp. 395-398, 1988.

[34] J. D. Mikkelsen, P. J. Larsen, C. Kruse-Larsen, M. M. T. O’Hare, and T. W. Schwartz, "Immunohistochemical and chromatographic identification of peptides derived from proneuropeptide Y in the human frontal cortex," Brain Research Bulletin, vol. 31, no. 3-4, pp. 415-425, 1993.

[35] J. D. Mikkelsen and M. M. O’Hare, “An immunohistochemical and chromatographic analysis of the distribution and processing of proneuropeptide $\mathrm{Y}$ in the rat suprachiasmatic nucleus," Peptides, vol. 12, no. 1, pp. 177-185, 1991.

[36] R. O'Rahilly, “The development of the epiphysis cerebri and the subcommissural complex in staged human embryos," Anatatomical Record, vol. 160, pp. 488-489, 1968.

[37] M. Møller, "The ultrastructure of the human fetal pineal gland. I. Cell types and blood vessels," Cell and Tissue Research, vol. 152, no. 1, pp. 13-30, 1974.

[38] L. W. Kneisley, M. A. Moskowitz, and H. G. Lynch, "Cervical spinal cord lesions disrupt the rhythm in human melatonin excretion," Journal of Neural Transmission, vol. 252, supplement 13, pp. 311-323, 1978.

[39] Y. Li, D. H. Jiang, M. L. Wang, D. R. Jiao, and S. F. Pang, "Rhythms of serum melatonin in patients with spinal lesions at the cervical, thoracic or lumbar region," Clinical Endocrinology, vol. 30, no. 1, pp. 47-56, 1989.

[40] J. M. Zeitzer, N. T. Ayas, S. A. Shea, R. Brown, and C. A. Czeisler, "Absence of detectable melatonin and preservation of cortisol and thyrotropin rhythms in tetraplegia," Journal of Clinical Endocrinology and Metabolism, vol. 85, no. 6, pp. 21892196, 2000.

[41] J. M. Zeitzer, N. T. Ayas, A. D. Wu, C. A. Czeisler, and R. Brown, "Bilateral oculosympathetic paresis associated with loss of nocturnal melatonin secretion in patients with spinal cord injury," Journal of Spinal Cord Medicine, vol. 28, no. 1, pp. 55-59, 2005.

[42] K. Scharenberg and L. Liss, "The histologic structure of the human pineal body," Progress in Brain Research C, vol. 10, pp. 193-217, 1965.

[43] J. A. Kappers, "The development, topographical relations and innervation of the epiphysis cerebri in the albino rat," Zeitschrift für Zellforschung und Mikroskopische Anatomie, vol. 52, no. 2, pp. 163-215, 1960.

[44] O. K. Rønnekleiv and M. Møller, "Brain-pineal nervous connections in the rat: an ultrastructure study following habenular lesion," Experimental Brain Research, vol. 37, no. 3, pp. 551-562, 1979. 
[45] H. W. Korf and U. Wagner, "Evidence for a nervous connection between the brain and the pineal organ in the guinea pig," Cell and Tissue Research, vol. 209, no. 3, pp. 505-510, 1980.

[46] M. Møller and H. W. Korf, "The origin of central pinealopetal nerve fibers in the mongolian gerbil as demonstrated by the retrograde transport of horseradish peroxidase," Cell and Tissue Research, vol. 230, no. 2, pp. 273-287, 1983.

[47] J. D. Mikkelson, B. Cozzi, and M. Møller, "Efferent projections from the lateral geniculate nucleus to the pineal complex of the Mongolian gerbil (Meriones unguiculatus)," Cell and Tissue Research, vol. 264, no. 1, pp. 95-102, 1991.

[48] D. Janik, J. D. Mikkelsen, and N. Mrosovsky, "Cellular colocalization of Fos and neuropeptide $\mathrm{Y}$ in the intergeniculate leaflet after nonphotic phase-shifting events," Brain Research, vol. 698, no. 1-2, pp. 137-145, 1995.

[49] G. C. Kenny, "The innervation of the mammaliam pineal body. (A comparative study)," Proceedings of the Australian Association of Neurologists, vol. 3, pp. 133-140, 1965.

[50] H. J. Romijn, "Structure and innervation of the pineal gland of the rabbit, Oryctolagus cuniculus (L.). III. An electron microscopic investigation of the innervation," Cell and Tissue Research, vol. 157, no. 1, pp. 25-51, 1975.

[51] G. G. Leblanc, B. A. Trimmer, and S. C. Landis, "Neuropeptide Y-like immunoreactivity in rat cranial parasympathetic neurons: coexistence with vasoactive intestinal peptide and choline acetyltransferase," Proceedings of the National Academy of Sciences of the United States of America, vol. 84, no. 10, pp. 3511-3515, 1987.

[52] J. Olcese, "Neuropeptide Y: an endogenous inhibitor of norepinephrine-stimulated melatonin secretion in the rat pineal gland," Journal of Neurochemistry, vol. 57, no. 3, pp. 943947, 1991.

[53] V. Simonneaux, A. Ouichou, C. Craft, and P. Pévet, "Presynaptic and postsynaptic effects of neuropeptide $\mathrm{Y}$ in the rat pineal gland," Journal of Neurochemistry, vol. 62, no. 6, pp. 2464-2471, 1994.

[54] B. B. Fredholm, I. Jansen, and L. Edvinsson, "Neuropeptide Y is a potent inhibitor of cyclic AMP accumulation in feline cerebral blood vessels," Acta Physiologica Scandinavica, vol. 124, no. 3, pp. 467-469, 1985.

[55] S. Kassis, M. Olasmaa, L. Terenius, and P. H. Fishman, "Neuropeptide Y inhibits cardiac adenylate cyclase through a pertussis toxin-sensitive G protein," Journal of Biological Chemistry, vol. 262, no. 8, pp. 3429-3431, 1987.

[56] J. D. Mikkelsen, F. Hauser, and J. Olcese, "Neuropeptide Y (NPY) and NPY receptors in the rat pineal gland," Advances in Experimental Medicine and Biology, vol. 460, pp. 95-107, 1999.

[57] S. M. Wai, P. M. Kindler, E. T. K. Lam, A. Zhang, and D. T. Yew, "Distribution of neuropeptide Y-immunoreactive neurons in the human brainstem, cerebellum, and cortex during development," Cellular and Molecular Neurobiology, vol. 24, no. 5, pp. 667-684, 2004.

[58] W. Z. Shen, "Distribution of neuropeptide Y in the developing human spinal cord," Neuroscience, vol. 62, no. 1, pp. 251-256, 1994.

[59] C. Ribelayga, P. Pévet, and V. Simonneaux, "Possible involvement of neuropeptide $\mathrm{Y}$ in the seasonal control of hydroxyindole-O-methyltransferase activity in the pineal gland of the European hamster (Cricetus cricetus)," Brain Research, vol. 801, no. 1-2, pp. 137-142, 1998.

[60] C. Ribelayga, P. Pévet, and V. Simonneaux, "Adrenergic and peptidergic regulations of hydroxyindole-O-methyltransferase activity in rat pineal gland," Brain Research, vol. 777, no. 1-2, pp. 247-250, 1997. 

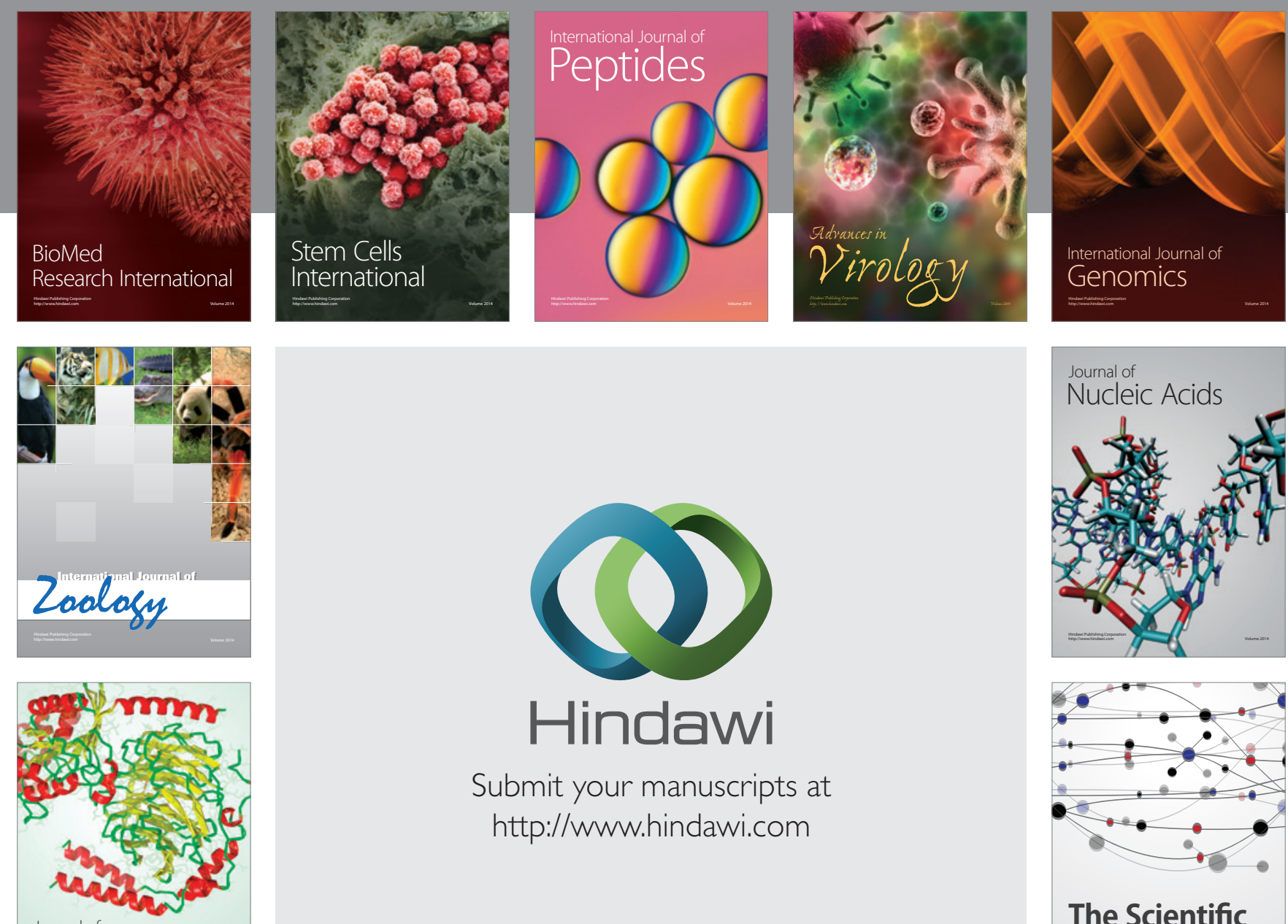

Submit your manuscripts at

http://www.hindawi.com

Journal of
Signal Transduction
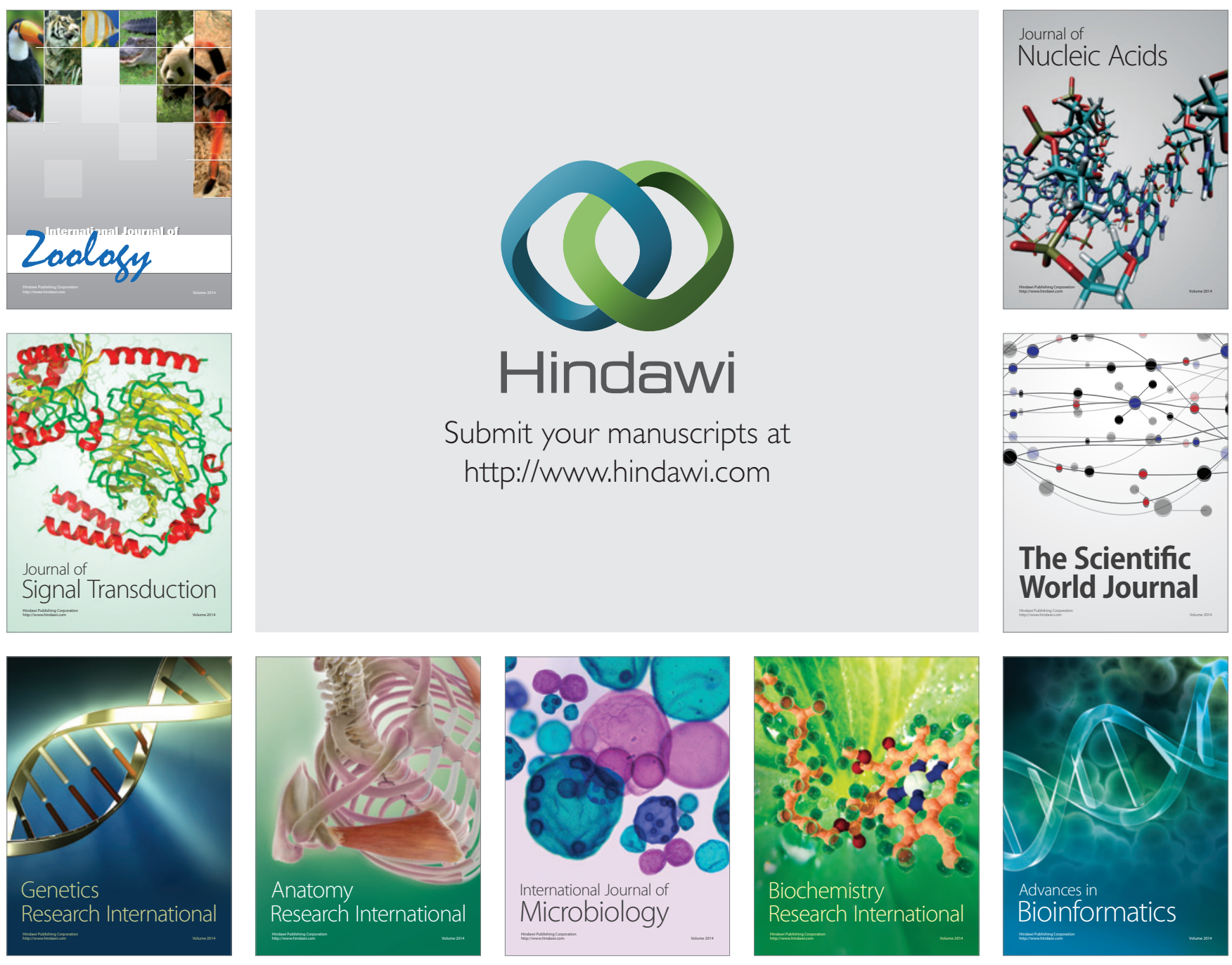

The Scientific World Journal
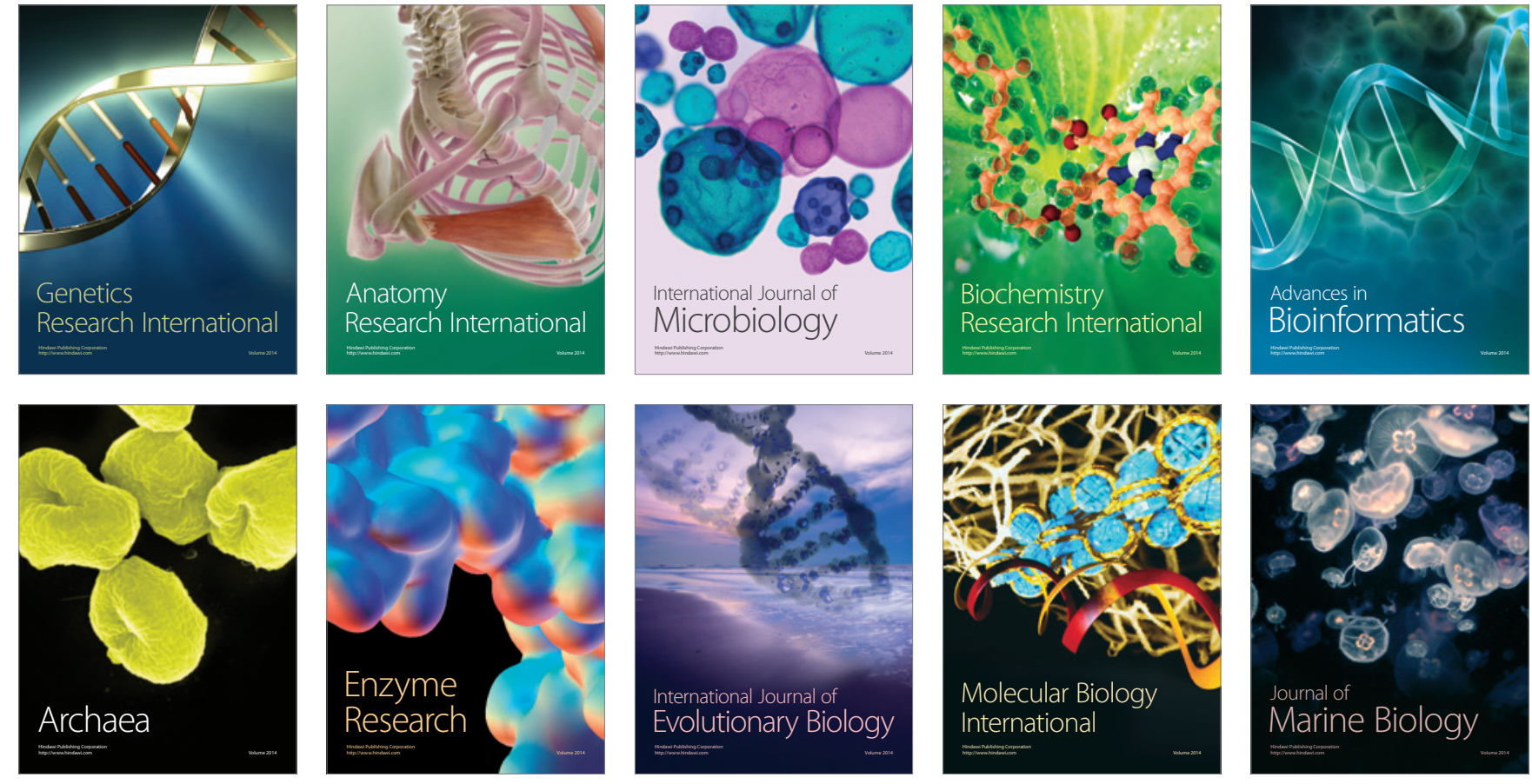